\title{
BTS
}

Leukemia

\section{DEBATE ROUND-TABLE}

\section{Appropriate controls for RT-PCR}

\section{Chairmen: V Kidd, Ph.D}

Dept of Tumor Cell Biology

St Judes Children's Research Hospital

332 N. Lauderdale

Memphis, TN 38101

USA

Fax: + 19014952381

\section{Prof T Lion, M.D., Ph.D}

Children's Cancer Research Institute

St Anna Children's Hospital

Kinderspitalgasse 6

A-1090 Wien

Austria

Fax: + 43140470489

In this issue, Leukemia presents the first contributions to the above-mentioned debate. The commentaries address facts and questions pertaining to the topic of RT-PCR controls discussed by Dr Kidd and Dr Lion in their opening comments published in earlier issues of Leukemia and reprinted in the following pages. The controversial viewpoints put forward by $\mathrm{V}$ Kidd and $\mathrm{T}$ Lion provided the stimulus for this debate, which is being pursued at a time when the use of RTPCR techniques is becoming widely disseminated, making it increasingly important to ensure that the laboratories involved provide reliable results. In this context, the use of adequate controls is certainly one of the critical issues.

We hope that the debate on this provocative topic will lead to a consensus enabling us to issue generally acceptable guidelines. However, a consensus will not be forced, and it is understood that guidelines need to be revised.

$N M B$, Editor 


\title{
OPENING ARTICLE BY T LION
}

\section{Control genes in reverse transcriptase-polymerase chain reaction assays}

\author{
T Lion
}

Children's Cancer Research Institute, St Anna Kinderspital, Kinderspitalgasse 6, A-1090 Vienna, Austria

Keywords: RT-PCR, $\beta$-actin, ABL, $\beta_{2}$-microglobulin

Examining the presence of amplifiable RNA is an essential control step in reverse transcriptase-polymerase chain reaction (RT-PCR) experiments. Amplification of $\beta$-actin gene sequences was a very commonly used approach to determining the availability of sufficiently intact RNA (cDNA) in the samples analyzed. It has been shown, however, that the human genome contains processed $\beta$-actin pseudogenes, ${ }^{1}$ which can result in the amplification of fragments from genomic DNA displaying similar size to those generated from a cDNA template. Since RNA preparations frequently contain traces of genomic DNA, amplification of a sequence from the $\beta$-actin gene can yield a PCR product of the expected size even in the absence of intact RNA (Figure 1 ; panel D). Therefore, $\beta$-actin may not be regarded as a suitable control for RNA integrity in RT-PCR analysis. ${ }^{2}$ Additionally, $\beta$-actin is a highly expressed gene and yields strong amplification signals even in the presence of very small template amounts. The use of a $\beta$-actin control may therefore lead to wrong interpretation of PCR assays if the gene investigated is expressed at a markedly lower level. ${ }^{3}$ These considerations have not been
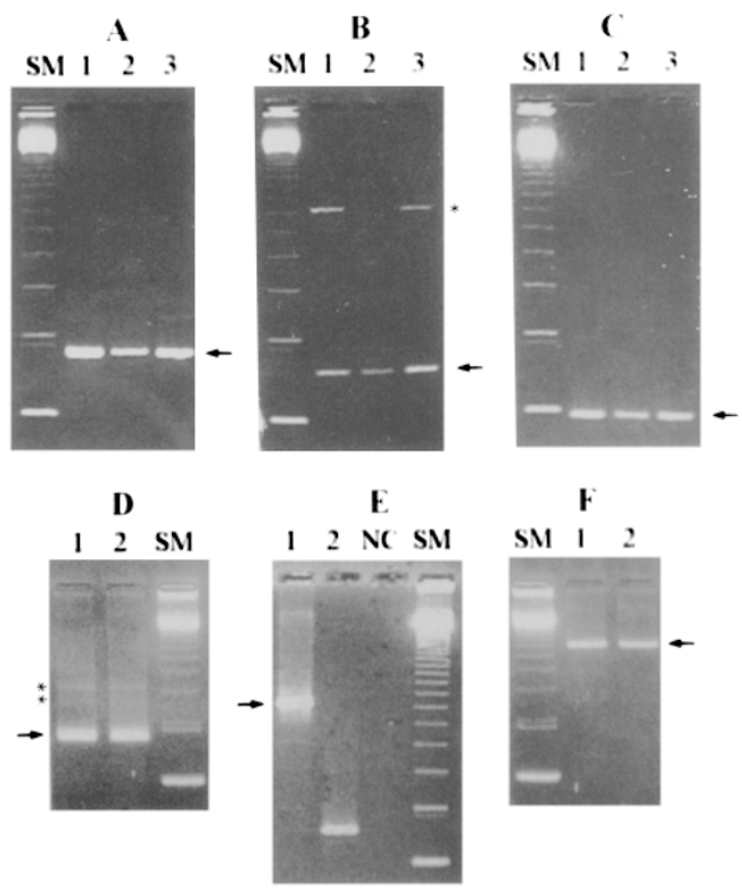

\section{$\mathbf{F}$}
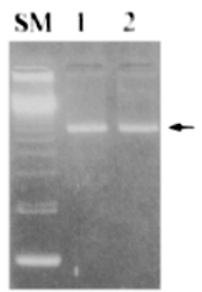

appreciated by a number of investigators, because the use of $\beta$-actin for validation of RT-PCR tests is still not uncommon.

It may not be possible to assess the integrity of a particular RNA species of interest with absolute certainty, but it is necessary to select control genes and primer combinations which will reveal the presence of amplifiable RNA and which will not yield PCR products of similar size from cDNA and genomic DNA templates. Different genes have been used as controls for the validity of RT-PCR results. ${ }^{4-8}$ For example, amplification of sequences from the $\mathrm{ABL}$ proto-oncogene has provided a convenient control system for RT-PCR assays in hematopoietic cells displaying the BCR-ABL rearrangement: ${ }^{9}$ when using a set of primers which will amplify a fragment across a $0.6 \mathrm{~kb}$ intron between exons 2 and 3, products of easily distinguishable size will be generated from genomic DNA and cDNA template sequences. Hence, in addition to demonstrating the presence of amplifiable RNA, this system

Figure 1 Agarose gel electrophoresis and visualization by ethidium bromide staining of PCR products generated from cDNA and genomic DNA templates with identical primer combinations. (panels A-C) RTPCR products from three human RNA specimens extracted from peripheral blood leukocytes as described. ${ }^{10} \mathrm{CDNA}$ from the three specimens (lanes 1-3) was amplified using primers derived from the human $\beta$-actin (panel A), ABL (panel B), and beta 2-microglobulin $\left(\beta_{2} \mathrm{MG}\right)$ (panel C) gene sequences. As shown in panel $B$, amplification of an $A B L$ gene sequence with primers spanning a $0.6 \mathrm{~kb}$ intron revealed the presence of contaminating genomic DNA in specimens 1 and 3 $\left.{ }_{*}\right)$ which escaped detection by the $\beta$-actin and $\beta_{2}$ MG primers used. Bands representing specific PCR products from the respective RNA/cDNA templates are marked by arrows. (Panels D-F) PCR from genomic DNA samples using the same sets of $\beta$-actin (panel D), ABL (panel E), and $\beta_{2} \mathrm{MG}$ (panel F) primers. Amplification of $\beta$-actin DNA in two different specimens (panel D, lanes 1 and 2) revealed products of identical size (arrow) to the RNA/cDNA-specific products displayed in panel $\mathrm{A}$ apparently due to the presence of $\beta$-actin pseudogenes in the human genome. Additional weak bands $(*)$ could have resulted from the presence of two short introns of approximately $0.1 \mathrm{~kb}$, one spanned by the primers employed, the other located within the sequence of the sense primer which shows homology at the $3^{\prime}$ end to the following intron sequence. In panel $\mathrm{E}$, lane 1 shows the expected $\mathrm{ABL}$ gene-derived DNA fragment (arrow) identical to that displayed in panel $B$ (lanes 1 and 3); lane 2 depicts the ABL amplification product from RNA/cDNA derived from the same cell sample. The bands displayed in panel $F$ (lanes 1 and 2) (arrow) reflect the presence of a $0.6 \mathrm{~kb}$ intron within the DNA segment amplified. In contrast to PCR analysis with the ABL primers, amplification with the $\beta_{2} \mathrm{MG}$ primers did not reveal a genomic DNA product in RT-PCR experiments in which the RNA/CDNA template was contaminated with genomic DNA (panel C, samples 1 and 3). This can be attributed to the fact that the $0.6 \mathrm{~kb}$ intron is located within the binding site of the $\beta_{2} \mathrm{MG}$ antisense primer, thus resulting in preferential annealing to a cDNA template. SM, size marker: 123 bp ladder. NC, Negative Control: PCR reaction mix lacking template nucleic acid. Primers used (size of RT-PCR product): $\beta$-actin sense: $5^{\prime}$-CTTCCTgggCATggAgTCC3'; antisense: 5'-CgCTCAggAggAgCAATgAT-3' (214 bp); ABL sense: 5'-AgCATCTgACTTTgAg-CC-3'; antisense: 5'-TTATAgCCTAAgACCCgg-3' (183 bp); $\beta_{2}$ MG sense: 5'-ACCCCCACTgAAAAAgATgA-3' antisense: 5'-ATCTTCAAACCTCCATgATg-3' (114 bp). 
will also reveal genomic DNA contaminants if present in the RNA preparation analyzed (Figure 1; panel B; lanes 1 and 3).

\section{References}

1 Leavitt J, Gunning P, Porreca P, Ng SY, Lin CS, Kedes L. Molecular cloning and characterisation of mutant and wild type $\beta$-actin alleles. Mol Cell Biol 1984; 4: 1961-1969.

2 Taylor JJ, Haesman PA. Control genes for reverse transcriptase/polymerase chain reaction (RT-PCR). Br J Haematol 1994; 86: 444-445.

3 Cross NCP, Lin F, Goldman JM. Appropriate controls for reverse transcription polymerase chain reaction (RT-PCR). Br J Haematol 1994; 87: 218 (letter).

4 Hongjun J, Zhang Q, Leung BS. Survey of oncogene and growth factor/receptor gene expression in cancer cells by intron-differential RNA/PCR. Biochem Biophys Res Commun 1990; 170: 569575.
5 Dveksler GS, Basile AA, Dieffenbach CW. Analysis of gene expression: use of oligonucleotide primers for glyceraldehyde-3phosphate dehydrogenase. PCR Meth Appl 1992; 1: 283-285.

6 Korninger $\mathrm{L}$ et al. PML-RAR $\alpha$ positivity in the bone marrow of patients with APL precedes haematological relapse by 2-3 months. Br J Haematol 1994; 88: 427-431.

7 Lion T, Gaiger A, Henn T, Hörth E, Haas OA, Geissler K, Gadner $\mathrm{H}$. Use of quantitative polymerase chain reaction to monitor residual disease in chronic myelogenous leukemia during treatment with interferon. Leukemia 1995; 9: 1353-1360.

8 Hochhaus A et al. Quantification of residual disease in chronic myelogenous leukemia patients on interferon- $\alpha$ therapy by competitive polymerase chain reaction. Blood 1996; 87: 1549-1555.

9 Melo JV, Kent NS, Yan SH, Goldman JM. Controls for reverse transcriptase-polymerase chain reaction amplification of BCR-ABL transcripts. Blood 1994; 84: 3984-3986 (letter).

10 Lion T, Prischl F, Haas OA, Pont J, Schwarzmeier J. Non-radioactive detection of the rearranged BCR/ABL sequences amplified by polymerase chain reaction. Leukemia 1991; 5: 156-159.

\title{
OPENING COMMENTARY FROM V KIDD
}

\section{Problematic controls for reverse transcription polymerase chain reactions (RT-PCR): an issue revisited}

\author{
VJ Kidd \\ Department of Tumor Cell Biology, St Jude Children's Research Hospital, 332 N Lauderdale, Memphis, TN 38101, USA
}

Dr Nicole Muller-Berat has asked Dr Lion and myself to gather opinions and introduce this debate concerning the need and appropriate types of controls for reverse transcriptase polymerase chain reaction (RT-PCR) experiments. Dr Lion raised his concerns regarding appropriate controls for demonstration of RNA integrity when using RT-PCR to analyze RNA expression. ${ }^{1}$ As pointed out, RT-PCR experiments can be subject to misinterpretation if suitable controls are not included in the design of the study. While many of Dr Lion's suggestions regarding the use of controls other than $\beta$-actin are valid and would undoubtedly improve controls for such experiments, it should also be noted that many of the commercially available RT-PCR 'kits' provide $\beta$-actin oligonucleotide primers as their internal control for RNA integrity. Thus, there is a long-standing reliance on the use of $\beta$-actin sequences as an appropriate control for RT-PCR reactions, and even though other genes may provide more suitable controls for such experiments, one has to consider whether this is the most practical solution. In addition, are there alternatives to those suggested by Dr Lion, and should we also consider other limitations of RT-PCR analysis? Furthermore, how do we deal with the tremendous number of RT-PCR studies that have been published using $\beta$ actin as a control (a short list of recent publications in Leukemia includes Refs 2-5)? First, it should be noted that many of these studies are still valid, as they have either been repeated by others (with identical results) or confirmed by additional experiments, including Western blotting and/or other biological assays to detect the level of the protein corresponding to the RNA detected by RT-PCR. ${ }^{2,3,6}$ However, limited quantities of patient material can severely limit such additional studies. ${ }^{4}$ Therefore, can the integrity of RNA be assessed, and the possible contamination of these samples with genomic DNA, even if $\beta$-actin is used as a control? We would like to solicit the views of other researchers regarding this point.

Secondly, the techniques used for purifying cellular RNA can influence the outcome of RT-PCR experiments. One point not addressed by Dr Lion is the method used in purifying RNA and the use of methods that eliminate, or significantly reduce, contaminating genomic DNA. Contamination of RNA with genomic DNA can be a formidable problem, but the quality of enzymes produced as recombinant proteins of FPLC purification, such as RNase-free DNAase, ${ }^{7}$ or, alternatively, the use of ultraviolet irradiation to eliminate genomic DNA (Ref. 8; and references therein) can improve the quality of the RNA being analyzed. Finally, oligonucleotide primers designed to amplify a region of a gene promoter element, perhaps the one corresponding to the gene whose expression is being analyzed by RT-PCR, can also definitively demonstrate whether an RNA template is free of contaminating genomic DNA. The DNA sequences encoded by promoters, which are not included in RNA transcripts and, therefore, can only be amplified by PCR if genomic DNA is present in the RNA sample. ${ }^{9}$

Finally, even if concerns regarding the contamination of RNA samples with DNA can be addressed, there are additional factors that may also influence RT-PCR analysis, and they are not eliminated by any of the methods described above. For example, there are mammalian genes that are frequently transcribed as heterogeneous nuclear (hn)-RNA species which are not always efficiently processed into functional 
mRNAs (Ref. 9; and references therein). If such RNA species are present in sufficient quantities, which has been observed for genes such as myogenin, ${ }^{9}$ interpretation of RT-PCR data can be adversely affected. This is a particular problem when either total cellular RNA, or even poly $(\mathrm{A})^{+}$-selected $\mathrm{RNA}$, is used as a template for RT-PCR experiments. These hn-RNAs can produce RT-PCR products that are identical in size to the genomic sequences from which they are expressed. ${ }^{9}$ To avoid such problems, several different approaches might be considered. Isolation of cytoplasmic RNA, commonly used to purify viral $\mathrm{RNAs}^{10}{ }^{10}$ can eliminate this problem in most cases. Alternatively, or concomitantly, one can design oligonucleotide primers for RT-PCR experiments that incorporate what is known about the mosaic structure of the gene being examined or used as a control. For example, if the intronic region between exons 2 and 3 of the gene being analyzed is $>10 \mathrm{~kb}$ in size, while the introns between exons 4 and 6 are $<500$ bp, primers can be designed that amplify the region encoded by exons 2 and 3 rather than the region encompassed by exons 4,5 or 6 . While this is not possible for all genes, the precipitous increase in information concerning the human genome is now making it possible for investigators to consider these approaches more frequently, and make appropriate choices before an experimental study is initiated.

It is hoped that the points Dr Lion and I have raised regarding the application of RT-PCR analyses to clinical/patient studies will stimulate other investigators to contribute to this debate as well. The quality of these experimental studies will, most certainly, be affected in a positive manner as a result.

\section{References}

1 Lion T. Controls for RNA integrity in reverse transcriptase-polymerase chain reaction assays. Leukemia 1996; 10: 1843.

2 Panayiotidis P, Ganeshaguru K, Foroni L, Hoffbrand AV. Expression and function of the FAS antigen in B chronic lymphocytic leukemia and hairy cell leukemia. Leukemia 1995; 9: $1227-1232$.

3 Metcalf D, Willson TA, Hilton DJ, Rago DI, Mifsud S. Production of hematopoietic regulatory factors in cultures of adult and fetal mouse organs: measurement by specific bioassays. Leukemia 1995; 9: 1556-1564.

4 Tsuchiya M, Migata M, Yamamori S, Kaneko Y, Adachi N, Nakamura T, Nobukuni Y, El-Sonbaty SS, Matsuda I. A late-appearing Philadelphia chromosome in acute lymphoblastic leukemia confirmed by expression of BCR-ABL mRNA. Leukemia 1995; 9: 1689-1693.

5 Jagasia AA, Sher DA, Le Moine PJ, Kim D-H, Moldwin RL, Smith SD, Diaz MO. Deletion or lack of expression of CDKN2 (CDK41/MTS1/INK4A) and MTS2 (INK4B) in acute lymphoblastic leukemia cell lines reflects the phenotype of the uncultured primary leukemia cells. Leukemia 1996; 10: 624-628.

7 Furrer B, Candrian U, Wieland P, Luthy J. Improving PCR efficiency. Nature 1990; 346: 324.

8 Sarkar G, Sommer SS. Removal of DNA contamination in polymerase chain reaction reagents by ultraviolet irradiation. In: Wu R (ed). Methods in Enzymology, (Vol 218). Academic Press: San Diego, 1993, pp 381-388.

9 Sanchez A, Robbins J. Unprocessed myogenin transcripts accumulate during mouse embryogenesis. J Biol Chem 1994; 269: $1587-1590$.

10 Ball LA. Cellular expression of a functional nodavirus RNA replicon from a vaccinia virus vector. J Virol 1992; 66: 23352345.

\section{REPLY FROM T LION}

\section{Appropriate controls for RT-PCR}

T Lion

Children's Cancer Research Institute (CCRI), St Anna Kinderspital, Kinderspitalgasse 6, A-1090, Vienna, Austria

To stimulate further discussion on this important topic, I would like to address some of the issues raised by Dr Kidd. The fact that for years $\beta$-actin controls were the most widely used approach to the assessment of RNA integrity certainly raises questions about the validity of earlier RT-PCR studies which relied on the amplification of sequences from this gene to determine the presence of intact RNA. The existence of processed $\beta$-actin pseudogenes in the human genome does not per se invalidate earlier experiments using $\beta$-actin as a control, but critical results, particularly if they were negative, might warrant judicious reassessment.

More importantly, however, we have to be concerned with the choice of appropriate controls in current and future RT-PCR studies. If, as pointed out by Dr Kidd, there are commercial RTPCR kits providing $\beta$-actin control primers, they need to be carefully tested for their ability to amplify products of similar size from genomic DNA and cDNA templates. We have shown that a set of $\beta$-actin primers facilitating amplification across two introns yielded a main product of identical size, regardless whether

Correspondence: T Lion, MD, PhD

Received 15 July 1996; accepted 1 August 1996
gDNA or cDNA were used as template. ${ }^{1}$

I do not believe that the method of RNA purification should greatly influence our selection of RT-PCR controls. Even if techniques were available which virtually eliminate the possibility of DNA contamination in RNA preparations, it might not be advisable to use control primers permitting amplification of similarsized products from gDNA and cDNA. For example, traces of gDNA in samples containing partially or largely degraded RNA could result in the misinterpretation of RT-PCR assays. Regardless of how small the likelihood of such a scenario might be, would it obviate the need for controls allowing specific assessment of amplifiable RNA in the samples analyzed?

In many instances, the presence of contaminating gDNA in an RNA preparation has no major adverse effect on the results of RT-PCR analysis. Therefore, it may not be essential to demonstrate whether an RNA template is free of gDNA by amplifying a target sequence with a set of DNA-specific primers. If the detection of gDNA in RNA samples is of interest, it might be more reasonable for many applications to design primers permitting amplification across a short intron sequence, if present in the target gene. Such primers will work both for 
cDNA and gDNA templates, but will yield products of different size depending on the type of template. In most experiments, however, the main requirement for RT-PCR controls is not proving the presence or absence of contaminating DNA, but assessing RNA integrity in the sample investigated. In a number of laboratories, the quality of total RNA preparations is determined by evaluating ribosomal RNA bands upon electrophoresis in (non-) denaturing agarose gels. The stability of various RNA species may be different, which makes controls for integrity of a specific target RNA of interest very difficult. In diagnostic assays for the detection of tumor cell-specific transcripts from rearranged genes, some investigators use control primers for mRNA of one or both genes involved. The primers are designed to amplify PCR products from a region located near the fusion point. ${ }^{1-3}$ This strategy permits detection of transcripts from the rearranged gene(s), but also of normal transcripts from the unaffected corresponding allele(s). Therefore, this approach does not allow absolutely reliable conclusions on the integrity of the actual target, the fusion mRNA. If it is not possible to assess the intactness of a specific RNA species of interest with absolute certainty, should the demonstration of amplifiable mRNA from a reference gene be regarded as the minimum requirement for RT-PCR controls? Should the primers used either span a large intron sequence to prevent amplification of gDNA or should they encompass one or more short introns to facilitate amplification of distinct products from cDNA and gDNA templates?

It is not the aim of this round table discussion to defend certain standpoints. Rather, the knowledge and the experience of different investigators should help us establish a consensus on this important topic, and ultimately, enable us to provide recommendations for appropriate controls in future RT-PCR studies.

\section{References}

1 Lion T. Control genes in reverse transcriptase-polymerase chain reaction assays. Leukemia 1996; 10: 1527-1528.

2 Korninger $\mathrm{L}$ et al. PML-RAR $\alpha$ positivity in the bone marrow of patients with APL precedes haematological relapse by 2-3 months. Br J Haematol 1994; 88: 427-431.

3 Melo JV, Kent NS, Yan SH, Goldman JM. Controls for reverse transcriptase-polymerase chain reaction amplification of BCR-ABL transcripts. Blood 1994; 84: 3984-3986 (letter).

\section{COMMENTARIES}

\section{Commentary from A Biondi}

\section{Centro M Tettamenti, Clinica Pediatrica Università Milano, HS Gerardo, Monza, Italy}

The issues raised by the recently proposed round-table ${ }^{1}$ are well-taken, and reinforce the need to reach a certain level of consensus, due to the dramatic increase in the use of reversetranscription polymerase chain reaction (RT-PCR) within diagnostic procedures. Although the steps to be considered for the proper control of a RT-PCR reaction are several, the issue of the availability of sufficiently intact RNA (cDNA) in the samples analyzed does represent the most relevant one. Most of the methods currently available for the preparation of mRNA from tissue specimens give intact mRNAs. In our experience, we found that the RNA extraction obtained by ultracentrifuge through a $\mathrm{CsCl}$ cushion gives the most reliable results (especially in terms of mRNA stability and DNA contamination) and is the most appropriate for residual disease study since it is necessary to use larger samples to achieve maximum sensitivity. The Chomczynski method has the advantage that an ultracentrifuge is not required and usually is the method of choice when a larger number of samples need to be processed. We control the quality of total RNA preparations by evaluating ribosomal bands using polyacrylamide or agarose gel electrophoresis, even in the routine diagnostic analysis samples (more that 600 per year) that we receive for the molecular identification of chromosomal translocations in hematological malignancies. ${ }^{2}$ This step can avoid further RT-PCR steps when clear degradation of RNA occurs. Can we define a reference gene for RT-PCR controls?
Although the amplification of the $\beta$-actin gene is currently proposed as a control in many commercial RT-PCR 'kits', we have abandoned ${ }^{3}$ its use for several reasons. The possibility to obtain positive results in the presence of RNA degradation may occur and is possibly explained by the amplification of traces of genomic DNA or by the amplification of the multiple $\beta$-actin pseudogenes present in the genome. Moreover this gene, as for most house-keeping genes, is expressed at a much higher level than most of the fusion mRNA currently detectable in hematological malignancies. This issue is even more relevant for the amplification of fusion mRNA (such as PML/RAR- $\alpha$ or MLL/AF4) whose RT-PCR is approximately one log less sensitive than the RT-PCR applied to different chimeric genes generated by other chromosomal abnormalities, such as the BCR/ABL. It is still an open question as to whether a common reference gene can be used as standard control for RT-PCR reactions, or whether the amplification of one of the two genes involved in the translocation would be preferable. As a practical guideline it is more feasible to use the amplification of the same gene for all the RT-PCR reactions to be performed routinely. In that context, the primers should be selected to facilitate amplification of distinct products from cDNA and genomic DNA. Within the BIOMED concerted action on the standardization of the molecular detection of chromosomal translocations in leukemia, we have agreed on the use of amplification of the $A B L$ proto-oncogene and to perform either PCR and RT-PCR with the same ABL primers, to check for DNA contamination as well as for RNA integrity. If one of the genes involved in the translocation is selected as control, the location of primers should encompass the breakpoint. In this way a single copy of the template gene per chro- 
mosome would be present at diagnosis either for the control or for the translocated allele. ${ }^{4}$ This would allow a theoretically identical copy number of templates for each reaction (ie PML/RAR- $\alpha$ vs normal allele) in a case with $100 \%$ leukemic cells. However, variations in RNA stability or other factors influencing the transcription rates may influence the amount of normal vs translocated allele copies. Another issue to be considered is whether deletion of the normal allele occurs in association with the translocation (as it occurs in most of the cases of acute lymphoblastic leukemia carrying the $t(12 ; 21)$ translocation), in which case amplification of the normal allele would not be successful. In conclusion, the discussion and the experience of different investigators should help

\section{Commentary from N Cross and J Melo}

Department of Haematology, Royal Postgraduate Medical School, Hammersmith Hospital, London, UK

For many years, $\beta$-actin has served as a robust control for the amount of RNA loaded onto Northern blots. Not surprisingly then, this gene appeared to be the natural choice as a control for RT-PCR analysis. The requirements for adequate control of the two techniques are, however, quite different and it has now become clear that PCR amplification of $\beta$-actin is an inadequate indicator of CDNA quality. This is for two reasons. First, the presence of multiple processed $\beta$-actin pseudogenes means that cDNA-sized products are amplified from genomic DNA, an almost ubiquitous contaminant of RNA preparations. ${ }^{1,2}$ Second, $\beta$-actin is expressed at a much higher level than most other genes. For samples that are small or partly degraded, the amount of target sequence may be below the level of PCR detection but, nevertheless, $\beta$-actin is still positive. ${ }^{3}$ In other words, use of $\beta$-actin as a control for RTPCR can lead to false-negative results.

We routinely use a single-step amplification of either the normal $\mathrm{ABL}$ or $\mathrm{BCR}$ genes to control for CDNA in qualitative PCR analysis. ${ }^{4,5}$ Both genes are ubiquitously expressed at a relatively low level and neither have pseudogenes. However, to enable results to be effectively standardized in quantitative

\section{Commentary from LAJ Janssen and CR Bartram}

\section{Institute for Human Genetics, University of Heidelberg, Germany}

In his invitation to a round-table discussion, Dr Lion raised several crucial questions with regard to the use of appropriate controls for RT-PCR analysis. ${ }^{1}$ Although an earlier discussion has led to the conclusion that the amplification of $\beta$-actin sequences is not a reliable test for the quality of the cDNA template, ${ }^{2,3}$ many investigators still use and publish results of studies based on $\beta$-actin controls. The possible misinterpretation of data is due to the presence of a large number of processed $\beta$-actin retropseudogenes in the human genome. Last year, Dirnhofer presented data showing that a genomic cDNA contamination as low as $0.1 \%$ is sufficient to produce a cDNA-like $\beta$-actin product after 35 cycles. In their hands every RNA sample, that did not undergo a DNAase treatment, define recommendations on this important topic, thus improving the quality of future RT-PCR studies.

\section{References}

1 Lion T. Control genes in reverse-transcriptase polymerase chain reaction assays. Leukemia 1996; 10: 1527-1528, and this issue.

2 Biondi A, Rambaldi A. Molecular diagnosis and monitoring of acute myeloid leukemia. Leukemia Res 1996; 10: 801-807.

3 Biondi A et al. Molecular monitoring of the $\mathrm{myl} /$ retinoic acid receptor- $\alpha$ fusion gene in acute promyelocytic leukemia by polymerase chain reaction. Blood 1992; 80: 492-497.

4 Melo JV, Kent NS, Yan SH, Goldman JM. Controls for reversetranscriptase polymerase chain reaction amplification of BCR-ABL transcripts. Blood 1994; 84: 3984-3986 (letter).

PCR analysis, for example in the context of minimal residual disease, we have demonstrated that it is also necessary to quantitate the control gene. ${ }^{6}$

\section{References}

1 Taylor J, Heasman PA. Control genes for reverse transcriptase/polymerase chain reaction (RT-PCR). Br J Haematol 1994; 86: 444

2 Melo JV, Kent NS, Yan X-H, Goldman JM. Controls for reverse transcription-polymerase chain reaction amplification of BCR-ABL transcripts. Blood 1994; 84: 3984.

3 Cross NCP, Lin F, Goldman JM. Appropriate controls for reverse transcription polymerase chain reaction (RT-PCR). Br J Haematol 1994; 87: 218.

4 Cross NCP, Hughes TP, Feng L, O'Shea P, Bungey J, Marks DI, Ferrant A, Martiat P, Goldman JM. Minimal residual disease after allogeneic bone marrow transplantation for chronic myeloid leukaemia in first chronic phase: correlations with acute graft-versushost disease and relapse. Br J Haematol 1993; 84: 67.

5 Cross NCP, Melo JV, Lin F, Goldman JM. An optimised multiplex polymerase chain reaction for detection of $\mathrm{BCR}-\mathrm{ABL}$ fusion mRNAs in haematological disorders. Leukemia 1994; 8: 186.

6 Hochhaus A, Lin F, Reiter A, Skladny H, van Rhee F, Shepherd PCA, Allan NC, Hehlmann R, Goldman JM, Cross NCP. Variable numbers of BCR-ABL transcripts persist in CML patients who achieve complete cytogenetic remission with interferon alpha. $\mathrm{Br}$ J Haematol 1995; 91: 126.

contained enough $\beta$-actin template to produce a signal, even if a mock cDNA synthesis was performed without the addition of reverse transcriptase. ${ }^{4}$

In our laboratory RT-PCR techniques are not only used in research projects, but also in a diagnostic setting. In the latter type of analysis we learned that the quality of the test depends on the use of an appropriate control. We believe that a good control should fulfil the following criteria: (1) The expression level of the control gene should correspond to the expression level of the gene product under investigation. The expression level of $\beta$-actin will most often be too high to be useful. ${ }^{3}$ In $C M L$ and $A L L$ patients, the expression level of the normal $A B L$ gene is comparable to the level of the BCR-ABL fusion gene and therefore can be regarded as an appropriate contol in this particular test. (2) RT-PCR products from control genes should be $\mathrm{mRNA} / \mathrm{CDNA}$ specific. It may be helpful if a differently sized product indicates the presence of genomic DNA (as recently discussed by Lion $^{5}$ ), but this is not a mandatory cri- 
terion for such a test. Moreover, absence of the genomic DNA specific product does not prove that there is no genomic contamination at all. (3) The use of an internal control is important in cases where the RT-PCR is performed to show presence or absence of a product, rather than to produce a product meant for further investigation. Factors like block temperature and Taq polymerase activity may differ between samples (eg due to a pipetting error, or abnormal condensation). Therefore, primers should be compatible and products should be distinguishable in size, allowing a duplex or multiplex RT-PCR.

We assume that these guidelines are already in operation in a great number of laboratories. Hopefully, others will agree to the relevance of these guidelines and apply them in future tests. We therefore appreciate the opportunity to reach consensus criteria through this round-table discussion.

\section{Commentary from E Macintyre and J Gabert on behalf of the diagnostic laboratories of the LALA94 Adult Acute Leukemia Trial (with the participation of C Bilhou-Nabera, JM Cayuela, N Frehoy, D Bories, C Bastard, P Martiat, F Davi, M Dupont, S Raynaud and S Hayette}

\section{Laboratoire de Biologie Cellulaire, Centre Anti-Cancéreux, Marseille, France}

First, we are grateful to Leukemia for initiating such a debate. Controls for RT-PCR are not only important for scientific reasons but also because therapeutic decisions are increasingly based on such molecular data. We believe that this round table will help to improve quality controls (QC) and define the necessary guidelines. Dr $\mathrm{V}$ Kidd and $\mathrm{Dr} \mathrm{T}$ Lion opened the debate about the appropriate control for checking RNA integrity and the quality of the reverse transcription step. ${ }^{1,2}$ We would like to share our experience of QC for RT-PCR in the context of a therapeutic trial.

In the French multicenter LALA94 trial for adult acute lymphoblastic leukemias (ALL), patient stratification for the second randomization after induction therapy is based on identification of poor prognosis factors defined in adult ALL. ${ }^{3,4}$ Among these, the $\mathrm{t}(9 ; 22), \mathrm{t}(1 ; 19)$ and $\mathrm{t}(4 ; 11)$ translocations are clearly independent poor prognostic factors. ${ }^{5}$ A group of 13 laboratories work as a network to identify the four corresponding fusion transcripts: BCR-ABL (m-BCR and M-BCR), MLL$\mathrm{AF} 4$ and E2A-PBX1, in order to provide the data before the second randomization (day 35). ${ }^{6}$ In this commentary, we describe the QC which we consider necessary during the RTPCR analyses of diagnostic samples with avoidance of false positive results as a priority. In addition to $\mathrm{QC}$, retrospective inter-laboratory controls on cells or cell lysates are being performed.

308 adult ALL (aged between 15 and 55 years) from 34 centers were included during a period of 28 months. Diagnostic blood and/or bone marrow samples, collected in heparin or EDTA tubes, were sent to one of the 13 reference laboratories by express mail either as fresh samples within $24 \mathrm{~h}$ or after Ficoll separation as cells in DMSO on dry ice. RT-PCR analyses were performed as previously described. ${ }^{7}$ Briefly, the standard protocol included an M-MLV reverse transciption reaction with random hexamers and $1 \mu \mathrm{g}$ of RNA. Common primers were used for the specific PCR reactions performed with 10 to $20 \%$ of the cDNA. ${ }^{6}$

The following precautions and positive and negative con-
References

1 Lion T. Appropriate controls for RT-PCR. Leukemia 1996; 10: 1843 , and this issue.

2 Taylor JJ, Heasman PA. Control genes for reverse transcriptase/polymerase chain reaction (RT-PCR). Br J Haematol 1994; 86: 444-447.

3 Cross NCP, Feng Lin, Goldman JM. Appropriate controls for reverse transcriptase chain reaction (RT-PCR). Br J Haematol 1994; 87: 218.

4 Dirnhofer S, Berger C, Untergasser G, Geley S, Berger P. Human $\beta$-actin retropseudogenes interfere with RT-PCR. Trends Genet 1995; 11: 380-381.

5 Lion T. Control genes in reverse transcriptase chain reaction assays. Leukemia 1996; 10: 1527-1528, and this issue.

trols were included to avoid false results. Firstly, the specificity of the PCR products analyzed on agarose gels was systematically confirmed either by a shifted PCR on the same cDNA, using an internal and an external primer (one laboratory) or by Southern blotting and hybridization with an internal oligoprobe labelled with a radioisotope $\left.{ }^{(32} \mathrm{P}\right)$ (three laboratories) or with biotin (nine laboratories). Nested PCR techniques were avoided because of the high risk of PCR contamination. ${ }^{8}$ Secondly, two positive controls were performed: (1) control for RNA integrity and quality of the RT reaction by amplification of an ubiquitously expressed gene, either the porphobilinogen decarboxylase (PBGD) gene or the Abelson (ABL) gene; (2) control for amplification of the specific fusion transcript: in each experiment pure RNA and a $10^{-1}$ dilution (RNA in RNA) for all positive cell lines (TOM-1 for m-BCR, RS 4-11 for MLLAF4 and IARC 318 for E2A-PBX1) were used as positive controls except for K562 which is known to express high levels of M-BCR mRNA and was therefore used at a $10^{-2}$ dilution. These cell lines were shared by all laboratories. Thirdly, because of the excellent sensitivity of PCR assays, the guidelines previously described were very strictly followed. ${ }^{9}$ Negative controls were included to detect possible cross-contamination, ie amplification was performed with all reagents except for nucleic acids in each experiment. Nevertheless, this control does not allow the detection of cross-contamination by PCR products in RNA samples. One way to minimize this problem is to use uracyl- $\mathrm{N}$-glycosylase prior to the PCR reaction. ${ }^{10}$ The incorporation of dUTP instead of dTTP allows specific degradation of possible PCR product contaminants before the amplification step. However, one has to be aware that this procedure does not eliminate the need to strictly follow the basic guidelines.

Apart from the classical guidelines, it was decided to adopt additional controls whenever a positive RT-PCR result for a fusion transcript is obtained. Firstly, a mock RT-PCR is performed from the same RNA, omitting the reverse transcriptase during the RT reaction, the so-called 'RT negative control'. If any contaminating PCR products were present in the RNA sample it would be amplified, thus allowing detection of cross-contamination. Secondly, if a positive RT-PCR result cannot be confirmed by another technique such as classical cytogenetics, fluorescent in situ hybridization (FISH) or Southern blotting, the analysis is repeated (extraction, RT and PCR) from a second aliquot of the same sample. If discrepant results are obtained from the two samples, material (preferably cellular) is sent to another laboratory within the group. An 
analysis is only considered positive if all QC are met. It is important to note, however, that none of these QC would allow the detection of a cellular cross-contamination between two patient samples during the separation step, emphasizing the importance of taking precautions at the very beginning of the analysis. The final interpretation is based on all clinical and biological data available.

After analysis of 283 patients within 28 months into the trial, 12 samples (4.5\%) were excluded because they did not meet the QC criteria: nine samples failed to show amplification of the ubiquitous gene (ABL or PBGD); the three others showed a positive signal for a fusion transcript (one $\mathrm{m}-\mathrm{BCR}$ and two M-BCR), but no cytogenetic data were available and we were unable to perform a second analysis due to lack of material.

Finally, an inter-laboratory QC program on coded samples was perfomed on 99 samples (36\% of the patients tested). The exchanges were performed between different laboratories rather than with a central reference laboratory. Every 4 months, randomly selected samples were exchanged based on the availability of material. This program showed that the data were concordant in 89 cases, nine results were excluded because they did not meet the QC (the RNA quality control was negative) and one discrepancy was reported for the $\mathrm{m}$ BCR transcript. The initial laboratory found a positive signal after one round of PCR followed by hybridization; the second laboratory performed a shifted PCR and only one primer set gave a positive band; the result was interpreted as negative. The karyotype was normal based on 20 mitoses examined. This patient relapsed with a $\mathrm{Ph}$ positive, $\mathrm{m}$-BCR positive ALL.

RT-PCR analyses are increasingly becoming part of the diagnostic or prognostic evaluation in current multicenter therapeutic trials for acute leukemias. Therapeutic decisions are being made on the basis of these molecular data alone, as in the Italian protocol for promyelocytic acute leukemia where patients are treated with all-trans retinoic acid only if they have the PML-RARa transcript. This also applies to some cases within the LALA94 protocol, when the karyotype is not available or it is a cryptic translocation. ${ }^{6,11,12}$ For acute myeloid leukemias, treated according to the UK-MCRAML12 and EORTC-AML12 protocols, RT-PCR analyses will be used in the future for therapeutic stratification. Patients with good prognostic genetic markers such as $t(8 ; 21), t(15 ; 17)$ or inv $(16)^{13}$ or their molecular equivalents could be excluded from allogeneic transplant in the first instance, as suggested recently at a consensus meeting. ${ }^{14}$ In this context, very strict QC for RT-PCR should be retained in order to avoid false- positive or negative results which may lead to inappropriate therapeutic decisions.

\section{References}

1 Kidd VJ. Problematic controls for reverse transcription polymerase chain reactions (RT-PCR): an issue revisited. Leukemia 1996; 10: 1841-1842, and this issue.

2 Lion T. Appropriate controls for RT-PCR. Leukemia 1996; 10: 1843, and this issue.

3 Baer MR, Bloomfield CD. Cytogenetics and oncogenes in leukemia. Curr Opin Oncol 1992; 4: 24-32.

4 Rowley JD. Recurring chromosome abnormalities in leukemia and lymphoma. Semin Hematol 1990; 27: 122-136.

5 Groupe Français de Cytogénétique Hématologique. Cytogenetic abnormalities in adult lymphoblastic leukemia: correlations with hematologic findings and outcome. A collaborative study of the Groupe Français de Cytogénétique Hématologique. Blood 1996; 87: 3135-3142.

6 Gabert J, Bilhou-Nabera C, Macintyre E, Cayuela J-M, Frenoy N, Bories D, Bastard C, Deschaseaux M, Davi F, Martiat P, Dupont M, Raynaud S, Charrin C, Fière D. Prospective multicentric molecular study for poor prognosis fusion transcripts at diagnosis in adult ALL. Blood 1996; 88: 76a.

7 Raynaud S, Mauvieux L, Cayuela J, Bastard C, Bilhou-Nabera C, Debuire B, Bories D, Boucheix C, Charrin C, Fière D, Gabert J. TEL/AML1 fusion gene is a rare event in adult acute lymphoblastic leukemia. Leukemia 1996; 10: 1529-1530.

8 Hughes T, Janssen JW, Morgan G, Martiat P, Saglio G, Pignon JM, Pignatti FP, Mills K, Keating A, Gluckman E et al. False-positive results with PCR to detect leukaemia-specific transcript. Lancet 1990; 335: 1037-1038 (letter).

9 Kwok S, Higuchi R. Avoiding false positives with PCR. Nature 1989; 339: 237-238, published erratum Nature 1989; 339: 490.

10 Longo N, Berninger NS, Hartley JL. Use of uracil DNA glycosylase to controle carry-over contaminations in polymerase chain reactions. Gene 1990; 93: 123-128.

11 Izraeli S, Janssen JW, Haas OA, Harbott J, Brok SF, Walther JU, Kovar H, Henn T, Ludwig WD, Reiter A et al. Detection and clinical relevance of genetic abnormalities in pediatric acute lymphoblastic leukemia: a comparison between cytogenetic and polymerase chain reaction analyses. Leukemia 1993; 7: 671-678.

12 Griesinger $F$, Elfers $H$, Ludwig WD, Falk M, Rieder $H$, Harbott J, Lampert F, Heinze B, Hoelzer D, Thiel E, Riehm H, Wörmann B, Fonatsch $\mathrm{C}$, Hiddemann W. Detection of HRX-FEL fusion transcripts in pre-pre-B-ALL with and without cytogenetic demonstration of $\mathrm{t}(4 ; 11)$. Leukemia 1994; 8: 542-548.

13 Dastugue N, Payen C, Lafage-Pochitaloff $M$, Bernard P, Leroux D, Huguet-Rigal F, Stoppa A-M, Marit G, Molina L, Michallet M, Maraninchi D, Atttal M, Reiffers J. Prognostic significance of karyotype in de novo adult acute myeloid leukemia. Leukemia 1995 9: 1491-1498.

14 Coiffier B, Philip T, Burnett K, Symann ML. Consensus conference on intensive chemotherapy plus hematopoietic stem-cell transplantation in malignancies: Lyon, France, June 4-6 1993. J Clin Oncol 1994; 12: 226-231.

\section{Commentary from C Mannhalter and G Mitterbauer}

Department of Laboratory Medicine, Division of Molecular Biology, Medical School of the University of Vienna, Austria

PCR and RT-PCR are used increasingly in diagnostic applications. This emphasizes the need for appropriate controls for the PCR reaction and for assessment of intact and amplifiable RNA.

One can expect that commercial RT-PCR kits will be used increasingly for numerous applications in the very near future. Thus, it is essential that these kits include adequate controls for RNA integrity as well as for detection of contamination of RNA with genomic DNA.

As Dr Lion pointed out, ${ }^{1}$ one should never rely on PCR control primers which allow amplification of similar-sized products from gDNA and cDNA, as is the case with certain $\beta$ actin primer pairs, ${ }^{2}$ not even when using very good RNA isolation methods. Treatment of RNA with RNAse-free DNAse, as recommended by Dr Kidd, ${ }^{3}$ has to be applied with caution. 
While contamination of DNAse with RNAse nowadays does not pose a problem, insufficient inactivation of the DNAse can cause problems, as it will lead to degradation of cDNA during cDNA synthesis. Phenol extraction of DNAse-treated RNA removes DNAses efficiently, but also results in loss of RNA which in case of small amounts of patient material is a serious disadvantage. As shown by a number of laboratories, the use of $\beta$-actin as control gene has major limitations in the detection of RNA degradation due to the much higher expression levels of $\beta$-actin compared to most target genes. ${ }^{4}$ Consequently, the detection of amplification signals from $\beta$-actin can lead to misinterpretation of the results. When testing for translocations, PCR amplification of a gene segment from one of the partner genes involved (eg abl, rar $\alpha$ ), which brackets a small intron, will be a good approach to controlling contamination of RNA with genomic DNA. ${ }^{5,6}$ The control genes should also have similar expression levels as the genes of interest.

\section{Commentary from P Páldi-Haris and J Földi}

\author{
National Institute of Haematology and Immunology, Depart- \\ ment of Molecular Genetics, Budapest, Hungary
}

Storage of samples at different stages of processing prior to RT-PCR analysis might affect the integrity of mRNA transcripts. We have therefore investigated the effect of storage on the stability of different types of mRNA.

In our laboratory, patients with chronic myeloid leukaemia are routinely analysed for the presence of the chimaeric bcrabl mRNA, and amplification of the normal abl gene message serves as a control for mRNA integrity in the samples tested. ${ }^{1}$ For preparation of total RNA, we use the method described by Chomczynski and Sacchi ${ }^{2}$ which allows interruption of the procedure at different stages, eg after addition of guanidine thiocyanate (GT) to the cells, or during one of the precipitation steps. We have tested the stability of the bcr-abl message under different storage conditions. Cells were dissolved in highly purified GT (Sigma G9277) and were divided into multiple aliquots. One aliquot was processed and analysed immediately, the others were placed at $-70^{\circ} \mathrm{C}$ for different periods of time prior to analysis by RT-PCR (Figure 1). In a different series of experiments, the samples were redissolved in GT after the first precipitation step, and were either deposited at $-70^{\circ} \mathrm{C}$ during the second precipitation step or were immediately submitted to RT-PCR analysis. After hybridisation of the PCR products to a ${ }^{32} \mathrm{P}$-labelled abl2-abl3 exon probe, the ratio between the chimaeric bcr-abl message and the normal abl message was determined by phosphoimage analysis. Evaluation of the bcr-abl/abl ratios in samples processed as indicated above revealed preferential degradation of the fusion mRNA during storage. The half-life of the bcrabl mRNA relative to the normal abl transcripts was 28 days in samples stored in GT, and 20 days in samples stored during the second precipitation step. These experiments demonstrate different stabilities of the bcr-abl and the abl transcripts under the storage conditions described. Techniques determining absolute quantities of the chimeric bcr-abl mRNA may therefore provide wrong results when storage of samples is involved in the procedure.

Similar experiments were performed with pml-rara and aml-
Appropriate controls for RT-PCR

$\checkmark$ Kidd and T Lion

\section{References}

1 Lion T. Control genes in reverse-transcriptase polymerase chain reaction assays. Leukemia 1996; 10: 1527-1528, and this issue.

2 Melo JV, Kent NS, Yan SH, Goldman JM. Controls for reversetranscriptase polymerase chain reaction amplification of BCR-ABL transcripts. Blood 1994; 84: 3984-3986 (letter).

3 Kidd VJ. Problematic controls for reverse transcription polymerase chain reactions (RT-PCR): an issue revisited. Leukemia 1996; 10: 1841-1842, and this issue.

4 Cross NCP, Feng L, Goldman JM. Appropriate controls for reverse transcription polymerase chain reaction (RT-PCR). Br J Haematol 1994; 87: 218 (letter).

5 Mitterbauer G et al. PCR monitoring of minimal residual leukemia after conventional chemotherapy and bone marrow transplantation in BCR-ABL-positive acute lymphoblastic leukemia. $\mathrm{Br}$ J Haematol 1995; 89: 937-941.

6 Korninger $\mathrm{L}$ et al. PML-RAR $\alpha$ positivity in the bone marrow of patients with APL precedes haematological relapse by $2-3$ months. Br J Haematol 1994; 88: 427-431.

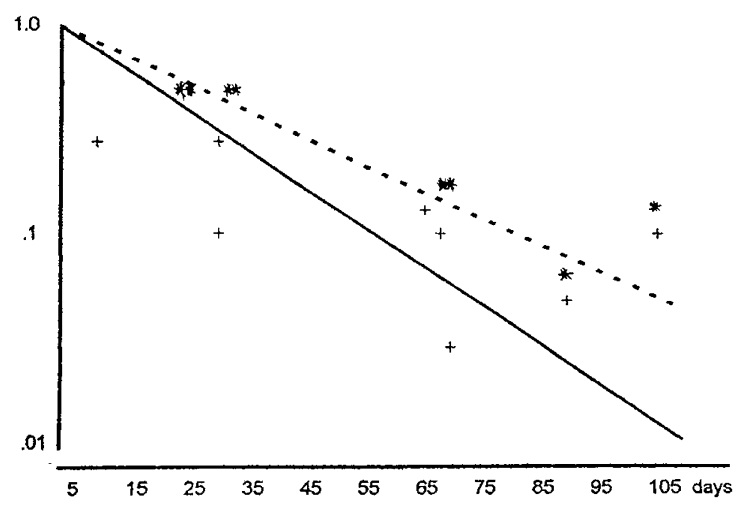

Figure 1 Decrease of relative bcr-abl mRNA amounts during storage of samples at $-70^{\circ} \mathrm{C}$ in GT (indicated by asterisks and the dashed line), and during the second precipitation step (indicated by crosses and the solid line). The bcr/abl ratio in individual samples is plotted against the time of storage.

eto chimeric mRNAs. Our preliminary results suggest that the degradation rate of the pml-rara message is similar to that of bcr-abl. The aml-eto message showed less pronounced, but detectable degradation. We conclude therefore that instability of chimaeric mRNAs during storage might be a common phenomenon.

Hence, in addition to the issues discussed by $\mathrm{T} \operatorname{Lion}^{3,4}$ and $\mathrm{V}$ Kidd ${ }^{5}$ differences in stability between the target gene and the control gene need to be considered in RT-PCR assays, particularly if storage of samples is involved.

\section{References}

1 Páldi-Haris P, Földi J. Experiences with the determination of chimaera bcr-abl messages in bone marrow and peripheral blood samples in chronic myeloid leukaemia. Br J Haematol 1995; 89: 684.

2 Chomczynski P, Sacchi M. Single step method of RNA isolation by acid guanidinium thiocyanate-phenol-chloroform extraction. Anal Biochem 1987; 162: 156.

3 Lion T. Control genes in reverse transcriptase-polymerase chain reaction assays. Leukemia 1996; 10: 1527, and this issue. 
4 Lion T. Appropriate controls for RT-PCR. Leukemia 1996: 10 1843, and this issue.

5 Kidd VJ. Problematic controls for reverse transcription polymerase chain reactions (RT-PCR): an issue revisited. Leukemia 1996; 10: 1841 , and this issue.

\section{Commentary from BA van der Reijden and JH Jansen}

Institute of Hematology, Erasmus University Rotterdam, The Netherlands

RT-PCR of specific mutations currently allows the identification of various types of leukemia cells, both at presentation and after treatment. For the detection of minimal residual disease, leukemia-specific transcripts must be detected in a small percentage of cells. To avoid false positive and negative results, various controls must be included. As it is well documented how to exclude false-positive results, we will not address this issue. To exclude false-negative results, controls for RNA integrity, cDNA synthesis and PCR amplification must be included.

Sometimes $\beta$-actin is still used to control RNA integrity and cDNA synthesis in RT-PCR assays. A major drawback is that positive results can be obtained even in the absence of RNA, due to processed $\beta$-actin pseudogenes present in contaminating genomic DNA. ${ }^{1}$ Another serious drawback of using $\beta$ actin is its high expression. Rare transcripts may not be amplified when the RNA is partially degraded, whereas amplification of $\beta$-actin sill occurs. Consequently, this leads to falsenegative results. It is therefore unacceptable to use $\beta$-actin or any highly expressed gene as controls for RNA integrity in RTPCR assays.

In acute promyelocytic leukemia, the PML gene is fused to the RAR $\alpha$ gene resulting in the expression of PML-RAR $\alpha$ fusion transcripts. The detection of the hybrid RNA after treatment is highly predictive of relapse. ${ }^{2}$ If more than one in $10^{3}-$ $10^{4}$ normal cells still expresses the fusion transcript after induction therapy, the chance of relapse is more than $90 \%$.

On the other hand, if less than one in $10^{3}-10^{4}$ cells expresses PML-RAR $\alpha$, the probability of disease-free survival is about $70-80 \%$. Since the prognostic value of the analysis has been validated at the level of one leukemic cell in $10^{3}$ $10^{4}$ normal cells, controls for both sensitivity and RNA integrity must be included. To prove that the level of detection is indeed one in $10^{3}-10^{4}$, a serial dilution of PML-RAR $\alpha$ positive cells in PML-RAR $\alpha$ negative cells has to be tested in each analysis. The expression of the non-rearranged RAR $\alpha$ gene is usually tested as a control for RNA integrity and cDNA synthesis. We occasionally detect decreases in sensitivity levels to less than one in $10^{3}$, although the control gene $(\operatorname{RAR} \alpha)$ is correctly amplified. This implies that PML-RAR $\alpha$ transcripts in patient samples can be missed, even when the RAR $\alpha$ control is positive, leading to false-negative results. Repeated testing of sequential patients samples should therefore be performed to minimize the effect of false-negative results. Nevertheless, we would welcome a better control for RNA integrity than $\operatorname{RAR} \alpha$.

In some analyses, accurate measurements of the number of tumor cell-specific molecules are required because such assays are of prognostic value. In patients with BCR-ABL-positive chronic myeloid leukemia, low levels of tumor cells can be present for prolonged periods of time without implying the need for clinical intervention. An increase of mRNA transcripts, measured by quantitative RT-PCR after allogeneic bone marrow transplantation, reliably predicts acceleration to an acute phase. The amount of BCR-ABL molecules can be determined using a competitor construct that is co-amplified in the RT-PCR. However, variations in RNA quality can affect the sensitivity of the assay, leading to unreliable results. These variations must be corrected by determining the amount of $B C R-A B L$ transcripts relative to a reference gene (eg ABL). The expression of the reference gene must also be analyzed by competitive RT-PCR using the same cDNA as used for the BCR-ABL detections. ${ }^{3}$ Although the controls in these quantitative assays are time-consuming, they are essential for reliable analysis. Persistence of fusion transcripts has also been found in other types of leukemia during prolonged clinical remission (eg AML1-ETO of CBFB-MYH11 in acute myeloid leukemia). ${ }^{4,5}$ The prognostic value of the presence of these fusion transcripts can probably only be determined by quantitative assays. The value of studies in which AML1-ETO and CBFB-MYH11 transcripts are not quantified must be questioned.

\section{References}

1 Lion T. Control genes in reverse-transcriptase polymerase chain reaction assays. Leukemia 1996; 10: 1527-1528, and this issue.

2 Jurcic JG, Miller WH Jr, DeBlasio A, Scheinberg DA, Warrel RP Jr. Prognostic significance of minimal residual disease detection and PML/RAR- $\alpha$ isoform type: long-term follow-up in acute promyelocytic leukemia (APL). Blood 1996; 10 (Suppl. 1): 635a.

3 Cross NCP, Hughes TP, Feng L, O'Shea P, Bungey J, Marks DI, Ferrant A, Martiat P, Goldman JM. Minimal residual disease after allogeneic bone marrow transplantation for chronic myeloid leukaemia in first chronic phase: correlations with acute graft-versushost disease and relapse. Br J Haematol 1993; 84: 67-74.

4 Nucifora G, Larson RA, Rowley JD. Persistence of the 8;21 translocation in patients with acute myeloid leukemia type M2 in longterm remission. Blood 1993; 82: 712-715.

5 Tobal K, Johnson PRE, Saunders MJ, Harrison CJ, Liu Yin JA. Detection of CBFB/MYH11 transcripts in patients with inversion and other abnormalities of chromosome 16 at presentation and remission. Br J Haematol 1995; 91: 104-108. 


\section{Preliminary conclusions from the first round of commentaries based on viewpoints shared by several contributing authors}

(1) $\beta$-Actin should no longer be regarded as an appropriate control gene for RT-PCR assays.

(2) Suitable control genes should have no pseudogenes in the human genome, and should be ubiquitously expressed at a level which does not exceed the expression level of the gene investigated.

(3) The selection of primers for PCR analysis of an appropriate control gene should either prevent amplification of template DNA or permit distinction between PCR products resulting from DNA and RNA templates, eg by amplification across an intron sequence.

(4) For a number of RT-PCR applications it is helpful to assess the overall quality of RNA preparations by evaluating ribosomal RNA bands after gel electrophoresis.

Scientists who wish to participate in the debate are invited to send their commentaries to either chairman with a copy to the Editor-in-Chief. 